\title{
Plasmatic Oxidative and Metabonomic Profile of Patients with Different Degrees of Biliary Acute Pancreatitis Severity
}

\author{
Pedro Silva-Vaz ${ }^{1,2,3,4, *(\mathbb{D})}$, Ivana Jarak ${ }^{5}$, Luís Rato ${ }^{6} \mathbb{D}^{\mathbb{D}}$, Pedro F. Oliveira ${ }^{7}\left(\mathbb{D}\right.$, Sara Morgado-Nunes ${ }^{4,8}(\mathbb{D}$, \\ Aida Paulino 2,3,4, Miguel Castelo-Branco 1,3,4 (D), Maria Filomena Botelho 9,10,11,12 (D), \\ José Guilherme Tralhão 9,10,11,12,13, Marco G. Alves 14 (D) and Ana Margarida Abrantes 9,10,11,12 (D)
}

1 Health Sciences Research Centre, University of Beira Interior (CICS-UBI), 6200-506 Covilhã, Portugal; mcbranco@fcsaude.ubi.pt

2 General Surgery Department, Hospital Amato Lusitano, Unidade Local de Saúde de Castelo Branco, 6000-085 Castelo Branco, Portugal; apaulino@ulscb.min-saude.pt

3 Faculty of Health Sciences, University of Beira Interior, 6200-506 Covilhã, Portugal

4 Clinical Academic Centre of Beiras (CACB), 6200-506 Covilhã, Portugal; sara@ipcb.pt

5 Department of Pharmaceutical Technology, Faculty of Pharmacy, University of Coimbra, 3000-548 Coimbra, Portugal; uc40924@uc.pt

6 Health School of the Polytechnic of Guarda, 6300-559 Guarda, Portugal; 1rato@ipg.pt

7 QOPNA \& LAQV, Department of Chemistry, University of Aveiro, 3810-193 Aveiro, Portugal; p.foliveira@ua.pt

8 Polytechnic Institute of Castelo Branco, Escola Superior de Gestão, 6000-084 Castelo Branco, Portugal

9 Biophysics Institute, Faculty of Medicina, University of Coimbra, 3000-548 Coimbra, Portugal;

check for
updates

Citation: Silva-Vaz, P.; Jarak, I.; Rato, L.; Oliveira, P.F.; Morgado-Nunes, S.; Paulino, A.; Castelo-Branco, M.; Botelho, M.F.; Tralhão, J.G.; Alves, M.G.; et al. Plasmatic Oxidative and Metabonomic Profile of Patients with Different Degrees of Biliary Acute Pancreatitis Severity. Antioxidants 2021, 10, 988. https://doi.org/ 10.3390/antiox10060988

Academic Editor: Joseph Cullen

Received: 16 May 2021

Accepted: 15 June 2021

Published: 21 June 2021

Publisher's Note: MDPI stays neutral with regard to jurisdictional claims in published maps and institutional affiliations.

Copyright: (c) 2021 by the authors. Licensee MDPI, Basel, Switzerland. This article is an open access article distributed under the terms and conditions of the Creative Commons Attribution (CC BY) license (https:/ / creativecommons.org/licenses/by/ $4.0 /)$.
mfbotelho@fmed.uc.pt(M.F.B.);igtralhao@fmed.uc.pt (J.G.T);mabrantes@fmed.uc.pt (A.M.A.)

10 Coimbra Institute for Clinical and Biomedical Research (iCBR) Area of Environment Genetics and Oncobiology (CIMAGO), Faculty of Medicina, University of Coimbra, 3000-548 Coimbra, Portugal

11 CNC.IBILI Consortium/Center for Innovation Biomedicine and Biotechnology (CIBB), University of Coimbra, 3000-548 Coimbra, Portugal

12 Clinical Academic Center of Coimbra (CACC), 3000-561 Coimbra, Portugal

13 Surgery Department, Centro Hospitalar e Universitário de Coimbra (CHUC), Faculty of Medicina, University Hospital, 3000-075 Coimbra, Portugal

14 Department of Anatomy and Unit for Multidisciplinary Research in Biomedicine (UMIB), Institute of Biomedical Sciences Abel Salazar (ICBAS), University of Porto, 4050-313 Porto, Portugal; maalves@icbas.up.pt

* Correspondence: pvaz@ulscb.min-saude.pt; Tel.: +351-966-498-337

\begin{abstract}
Acute pancreatitis (AP) is an inflammatory process of the pancreas with variable involvement of the pancreatic and peripancreatic tissues and remote organ systems. The main goal of this study was to evaluate the inflammatory biomarkers, oxidative stress (OS), and plasma metabolome of patients with different degrees of biliary AP severity to improve its prognosis. Twenty-nine patients with biliary AP and 11 healthy controls were enrolled in this study. We analyzed several inflammatory biomarkers, multifactorial scores, reactive oxygen species (ROS), antioxidants defenses, and the plasma metabolome of biliary AP and healthy controls. Hepcidin (1.00), CRP (0.94), and SIRI (0.87) were the most accurate serological biomarkers of AP severity. OS played a pivotal role in the initial phase of AP, with significant changes in ROS and antioxidant defenses relating to AP severity. Phenylalanine $(p<0.05)$, threonine $(p<0.05)$, and lipids $(p<0.01)$ showed significant changes in AP severity. The role of hepcidin and SIRI were confirmed as new prognostic biomarkers of biliary AP. OS appears to have a role in the onset and progression of the AP process. Overall, this study identified several metabolites that may predict the onset and progression of biliary AP severity, constituting the first metabonomic study in the field of biliary AP.
\end{abstract}

Keywords: acute biliary pancreatitis; inflammation; prognostic; severity; hepcidin; systemic inflammatory response index; oxidative stress; metabonomics 


\section{Introduction}

Acute pancreatitis (AP) is an inflammatory disorder of the exocrine pancreas with high morbidity and mortality if associated with local and systemic complications [1,2]. Most patients present with mild self-limited AP with a good prognosis [3]. However, $15-20 \%$ progress to a severe AP with pancreatic necrosis and high morbidity and mortality associated with systemic inflammatory response syndrome (SIRS) and multiple organ failure [4,5]. There has been an increasing incidence in the last decades, although with an unchanged mortality rate [6]. The overall mortality of AP is less than $5 \%$, though severe AP is associated with a mortality up to $30-50 \%[1,7]$. The most common causes of AP are gallstones and alcohol [6]. In the Mediterranean and other southern European countries, including Portugal, gallstones are the dominant etiology [8].

Several theories associated with the early pathogenesis of AP have been described, such as the intra-acinar and ductal activation of proteolytic enzymes, leukocyte chemotaxis, the release of pro- and anti-inflammatory cytokines, oxidative stress (OS), mitochondrial dysfunction, gallstone migration, microcirculation injury, as well as bacterial translocation to the pancreas and systemic circulation $[9,10]$. Nevertheless, the molecular mechanisms by which those effects are mediated remain unknown.

AP is associated with a high variability of severity, and although an early identification of patients who will develop severe AP is crucial, this identification remains a great challenge. Determination of AP prognosis is crucial to optimize the initial therapeutic approach and decrease mortality. Several serological biomarkers and scores have been described, namely C-reactive protein (CRP) [11], hepcidin [12,13], procalcitonin (PCT) [14], the systemic inflammatory response index (SIRI) [13], the bedside index for severity in acute pancreatitis (BISAP) [15], SIRS [16], and the modified Marshall score (MMS) [17].

The role of reactive oxygen species (ROS) in the pathophysiology of AP has been demonstrated $[18,19]$ and occurs in the early stages of this inflammatory process [20]. However, it is not clear whether ROS act as mediators or initiate the complex cascade that leads to AP and, thus, the exact role of OS in the development of AP remains unclear [21]. OS is presently considered a critical mediator of the early local events related to AP and the associated SIRS [22]. Mitochondria are susceptible to OS, and mitochondrial dysfunction is often used as a specific biomarker of oxidant exposure [23]. In experimental models of $\mathrm{AP}$, acinar cells were shown to die through necrosis and apoptosis, pathways linked to mitochondrial dysfunction [24]. Others suggest that mitochondrial dysfunction is associated with systemic inflammatory processes [25], but the mechanisms remain largely unknown. Thus, OS-associated events and biomarkers in AP remain to be defined.

The determination of metabolite changes that describe a biological phenotype based on ${ }^{1} \mathrm{H}$ nuclear magnetic resonance (NMR) spectroscopy has been widely applied to define prognostic biofluid profiles for physiological or pathological states [26]. In inflammatory disorders, such as AP, only a few studies of metabolome have been reported. Villaseñor et al. [27] studied the metabolic phenotype in urine and plasma samples of 15 patients with AP. The etiologies of the AP group were gallstones (6/15) and alcohol $(9 / 15)$. They found changes in alanine, valine, and hippurate in patients with AP and concluded that these metabolites have the potential to serve as diagnostic tools. Lusczek et al. [28] evaluated the potential of urinary ${ }^{1} \mathrm{H}-\mathrm{NMR}$ metabonomics in the diagnosis of AP. The authors analyzed five patients with AP and concluded that it is possible to obtain a distinct metabolome in AP patients' urine samples compared to healthy controls. That study identified citrate as the primary metabolite associated with the inflammatory AP state and alcohol consumption. Xu et al. [29] studied the serum metabolomics of mild AP in 38 patients. Although the authors did not specify the etiology of AP patients, by using the chromatography-high-resolution mass spectrometry (UPLC-HRMS) technique, they identified decanyl choline, dodecanol, and 2-tetradecanone as diagnosis metabolites, and sphinganine, L-thyronine, glycocholic acid and 2-tetradecanone as therapeutic response metabolites. Xiao et al. [30], using gas-chromatography/mass spectrometry (GS-MS), identified several metabolites, such as 3-hydroxubutyric, D-glucose, and hexadecenoic acid, 
with potential clinical relevance for diagnosis in 40 patients with AP. It was suggested 3-hydroxybutyric acid and citric acid have a prognosis value. Huang et al. [31] studied three AP etiologies (29 patients with hyperlipidemia, 20 with alcoholic AP, and 27 with biliary AP). They concluded that L-tyrosine, octadecanoic acid, cholesterol, glycerol 1hexadecanoate, and L-lactic acid are metabolites with potential diagnosis relevance and (R)-3-hydroxybutyric acid and mannitol could distinguished AP from the healthy group. However, this study did not evaluate the characteristics between each group of AP patients, nor was the prognosis of AP severity taken into account. These five papers described several metabolites, mainly as diagnostic tools, but only one specifically studied the subgroup of patients with biliary AP, comparing it with other AP etiologies.

This study aimed to evaluate the pathophysiology of AP by analyzing the inflammatory biomarkers and multifactorial scores, OS, and plasma metabolome of biliary AP patients and healthy controls. It is intended to contribute to a better understanding of biliary $\mathrm{AP}^{\prime}$ 's pathophysiology and thus improve prognosis.

\section{Materials and Methods}

\subsection{Participants}

Study participants were recruited among patients with biliary AP admitted to the Department of General Surgery of the Hospital Amato Lusitano of Unidade Local de Saúde de Castelo Branco, University Teaching Hospital, Castelo Branco, Portugal. Twenty-nine patients and 11 healthy controls were considered for the study. The study protocol was approved by the local ethics committee (reference number 10294/15) and was conducted in compliance with the Declaration of Helsinki. Signed informed consent was obtained from all participants.

\subsection{Study Design}

Subjects with AP that accepted the request to participate and met the eligibility criteria of admission were recruited between November 2015 and January 2016. AP was defined according to the revised Atlanta classification (RAC). At least two of the following three features must have been present: (1) abdominal pain consistent with AP; (2) serum lipase activity (or amylase activity) at least three times greater than the upper limit of a normal value; (3) and characteristics findings of AP on contrast-enhanced computed tomography (CECT) and less commonly on magnetic resonance imaging (MRI) or transabdominal ultrasonography (US) [17].

All adult patients ( $\geq 18$ years old) with biliary AP were included. Patients with other causes of AP except biliary, recurrent AP, chronic pancreatitis, pancreatitis due to malignancy, pregnant patients, patients with time from onset of disease to presentation in the emergency room greater than $24 \mathrm{~h}$, and patients being hospitalized for more than $24 \mathrm{~h}$ at the time of recruitment were excluded. For an etiological confirmation of AP, the patients underwent US with identification of gallstones or microlithiasis. After the US, patients with etiological doubt underwent endoscopic ultrasonography to exclude microlithiasis and characterize the biliary tree.

Local and systemic complications were defined according to the RAC [17]. The severity of AP was defined according to the RAC: mild (no organ failure or no local or systemic complications), moderately severe (organ failure that resolves within $48 \mathrm{~h}$ and the present local or systemic complications or both without persistent organ failure), and severe (presence of persistent organ failure or SIRS). Overall, this study included 40 individuals: mild $(n=10)$, moderately severe $(n=9)$, and severe $(n=10)$ AP patients and healthy controls $(n=11)$.

All subjects included in this study were evaluated for comorbidities by applying the Charlson comorbidity index (CCI). This index is the most frequently used tool to measure co-existing diseases and it has been validated for predicting the risk of mortality, disability, hospitalization, and length of hospital stay in several clinical settings [32]. CCI is 
age-dependent and evaluates several pathological conditions, including cardiovascular, respiratory, liver, and peptic diseases as well as diabetes and AIDS [33].

\subsection{Analysis of Biomarkers and Scores Systems}

Blood samples were collected from each patient that had been fasting for at least $6 \mathrm{~h}$ on admission and after $48 \mathrm{~h}$ of onset of symptoms, drawn into $5 \mathrm{~mL}$ heparin-treated tubes and centrifuged for $10 \mathrm{~min}$ at $1500 \times \mathrm{g}$. The plasma was then collected and stored at $-80{ }^{\circ} \mathrm{C}$ until analysis. Lipase (U/L), amylase (U/L), CRP (mg/dL9, PCT (ng/dL), white blood cells $\left(\mathrm{WBC}, 10^{3} / \mu \mathrm{L}\right)$, neutrophil $\left(\mathrm{N}, 10^{3} / \mu \mathrm{L}\right)$, lymphocyte $\left(\mathrm{L}, 10^{3} / \mu \mathrm{L}\right)$, monocyte $\left(\mathrm{M}, 10^{3} / \mu \mathrm{L}\right)$, calcium $(\mathrm{mg} / \mathrm{dL})$, albumin $(\mathrm{g} / \mathrm{dL})$, total proteins $(\mathrm{g} / \mathrm{dL})$, and hepcidin $(\mathrm{ng} / \mathrm{mL})$ were analyzed following certified analysis at the Department of Clinical Pathology, Hospital Amato Lusitano of the Unidade Local de Saúde de Castelo Branco. Neutrophil/lymphocyte $(\mathrm{N} / \mathrm{L})$ ratio and SIRI were calculated.

The BISAP score was described in 2008 and consists of a simple, early assessment of mortality risk in patients with AP. It evaluated five parameters: blood urea nitrogen (BUN), mental status, SIRS, age, and pleural effusion. The cut-off used to assess the mortality risk and severity of AP was $\geq 3$. SIRS is a simple and widely used score in a clinical setting. It evaluates four parameters: temperature, respiratory rate, pulse, and WBCs. This score is defined by the presence of $\geq 2$ of the described parameters. The MMS allows for the assessment of multiorgan failure in AP. Organ failures includes one or more of the following parameters: cardiovascular, respiratory, and kidney failure. Multiorgan failure is present to a cut-off of $\geq 2$. In the present study, all three scores were assessed on admission and $48 \mathrm{~h}$ after onset of symptoms.

\subsection{Oxidative Stress Evaluation}

Carbonyl groups, protein nitration, and lipid peroxidation are usually used as biomarkers for OS-related alterations in proteins and lipids. We evaluated, on admission: 2,4dinitrophenyl (2,4-DNP), 3-nitrotyrosine (3-NO), and 4-hydroxynonenal (4-HNE), respectively. The content of these adducts in plasma samples was evaluated using specific antibodies via slot-blot as previously described [34,35]. The activity of several antioxidant defense enzymes was also evaluated, namely glutathione peroxidase (GPx), glutathione reductase (GR), superoxide dismutase (SOD), and catalase (CAT). GPx and GR concentrations in plasma samples were determined using previously described methods [36]. The assay for SOD activity was based on the reaction in which SOD reduces the superoxide anion to hydrogen peroxide and oxygen, using a method previously described [37]. The CAT activity assay was based on the measurement of hydrogen peroxide produced by the action of CAT.

\subsection{Proton NMR $\left({ }^{1} H-N M R\right)$ Spectroscopy}

${ }^{1} \mathrm{H}-\mathrm{NMR}$ spectra of plasma samples were acquired and quantified as previously described [38]. Sodium fumarate (final concentration of $1 \mathrm{mM}$ ) was used as an internal reference $(6.50 \mathrm{ppm})$ to quantify the following metabolites present in plasma samples media (multiplet, ppm). Relative areas of ${ }^{1} \mathrm{~h}-\mathrm{NMR}$ resonances and metabolites concentrations were quantified as previously described [38]. In brief, plasma samples composed of patients with biliary AP, collected on admission, and healthy subjects for the control group were analyzed. These samples were thawed, homogenized using a vortex, and centrifuged (9200 rpm, $5 \mathrm{~min}$ ). NMR spectra were acquired on a Varian Inova $600 \mathrm{MHz}$ (14.1 T) spectrometer equipped with a $3 \mathrm{~mm}$ QXI probe with a z-water presaturation. Water saturation frequencies were optimized for each sample. Chemical shifts were internally referenced to a glucose doublet at $5.23 \mathrm{ppm}$. Metabolite assignment was based on a comparison with previously published data and reference spectra available in public databases such as HMBD [39]. Additionally, 2D homonuclear TOCSY spectra were recorded to help with spectral assignment [40]. 
Data matrices for multivariate analysis were created in AMIX-Viewer (version 3.9.15, BrukerBiospin, Rheinstetten) using all intensity values in the $0.75-8.5$ ppm region with the exclusion of water and fumarate regions as well as the regions without signal. Processed spectra were aligned to minimize shift variations [41] and normalized by integral area to account for matrix dilution effects and experimental conditions [42]. Multivariate analysis was performed in Simca 14 (Umetrics, Umea, Sweden) on unit-variance scaled data matrices. Principal component analysis (PCA) evaluated the initial data structure, followed by partial least squares discriminant analysis (PLS-DA) to identify metabolite contribution to class separation. PLS-DA loadings were calculated by multiplying the variable weights (w) with the respective standard deviations and color-coded according to the size of variable importance to projection values (VIP). Metabolites with VIP $>1$ were considered relevant to group separation. Default sevenfold cross-validation and permutation tests [43] were used to validate the observed variation $\left(R^{2}\right)$ and predictive potential $\left(Q^{2}\right)$ of PLS-DA models. Additionally, well-resolved peaks of relevant metabolites were integrated (AMIX-Viewer, version 3.9.15, BrukerBiospin, Rheinstetten) and normalized by integral areas. Biological effects for normalized areas were estimated by calculating effect size. Additionally, they were analyzed via two-way ANOVA followed by Tukey's post hoc test (Graph-Pad Prism 6 for Windows, Graph Pad Software, La Jolla, California, USA, www.graphpad.com, accessed on 15 December 2020).

\subsection{Statistical Analysis}

Results are expressed in mean (SD) \pm standard error of the mean (SEM), median (Q1, Q3), or $\mathrm{n}(\%)$. Normality was assessed using the Shapiro-Wilk test. Regarding the quantitative variables, the central tendency was compared using Student's $t$ or MannWhitney tests ( 2 categories) or ANOVA or the Kruskal-Wallis test ( $>2$ categories). In qualitative variables, associations were verified using the Chi-squared test, with Fisher's correction when necessary. Receiver operating characteristics (ROC) curves were calculated to assess the prognostic accuracy and determine the best cut-off points. A $p<0.05$ indicated statistical significance. Statistical analysis was performed using SPSS 25.0 (SPSS, Chicago, IL, USA).

\section{Results}

\subsection{Clinical Data}

The baseline characteristics of healthy controls $(n=11)$ and biliary AP patients: mild AP $(n=19)$, moderately severe AP $(n=9)$, and severe AP $(n=10)$ are shown in Table 1. There were no significant differences in the demographic features between the control group and biliary AP patients. There were also no differences between the demographic characteristics in the three degrees of AP severity, as expressed in Table 1.

Table 1. Baseline characteristics of healthy controls and biliary AP patients included in the study. ( ${ }^{\ddagger}$ Mann-Whitney test; 㧊 Chi-squared test; 㧊 Kruskal-Wallis test).

\begin{tabular}{|c|c|c|c|c|c|c|c|}
\hline & $\begin{array}{l}\text { Control } \\
(n=11)\end{array}$ & $\begin{array}{l}\text { Sample } \\
(n=29)\end{array}$ & $p$ & $\begin{array}{l}\text { Mild AP } \\
(n=10)\end{array}$ & $\begin{array}{l}\text { Moderately Severe AP } \\
\qquad(n=9)\end{array}$ & $\begin{array}{l}\text { Severe AP } \\
\quad(n=10)\end{array}$ & $p$ \\
\hline Age (years) & $69 \pm 14.6$ & $65 \pm 18.9$ & $0.65 \ddagger$ & $54 \pm 16.8$ & $69 \pm 17.2$ & $73 \pm 18.7$ & 0.53 㧊 \\
\hline Female sex & $6(54.5 \%)$ & $20(69 \%)$ & 0.41 㧊 & $8(80 \%)$ & $6(66.7 \%)$ & $6(60 \%)$ & 0.39 护 \\
\hline $\mathrm{BMI}\left(\mathrm{kg} / \mathrm{m}^{2}\right)$ & $26.7 \pm 3.0$ & $26.7 \pm 3.8$ & $0.98 \ddagger$ & $27.0 \pm 2.9$ & $26.4 \pm 4.6$ & $26.6 \pm 4.0$ & 0.92 执 \\
\hline $\mathrm{BMI} \geq 30 \mathrm{~kg} / \mathrm{m}^{2}$ & $2(18.2 \%)$ & $6(20.7 \%)$ & 0.91 㧊 & $2(20 \%)$ & $2(22.2 \%)$ & $2(20 \%)$ & 0.91 抽 \\
\hline $\mathrm{CCI}$ & $3(1-4)$ & $3(1-4)$ & $0.49 \ddagger$ & $1(0-2)$ & $3(2-4)$ & $3(1-4)$ & 0.49 㧊 \\
\hline Hospital stay (days) & & $12 \pm 7.8$ & - & $6 \pm 2.5$ & $11 \pm 5.0$ & $18 \pm 8.7$ & - \\
\hline Mortality & & $3(10.3 \%)$ & & & & $3(30 \%)$ & \\
\hline
\end{tabular}

AP: acute pancreatitis; BMI: body mass index; CCI: Charlson comorbidities index.

Several biochemical markers and multifactorial scores were assessed, both on admission and $48 \mathrm{~h}$ after onset of symptoms, which are expressed in Table 2. 
Table 2. Several biochemical markers and multifactorial scores of healthy controls and biliary AP patients included in the study. ( ${ }^{\ddagger}$ Kruskal-Wallis test).

\begin{tabular}{|c|c|c|c|c|c|c|c|}
\hline & $\begin{array}{l}\text { Controls } \\
(n=11)\end{array}$ & Time & $\begin{array}{l}\text { Sample } \\
(n=29)\end{array}$ & $\begin{array}{l}\text { Mild AP } \\
(n=10)\end{array}$ & $\begin{array}{l}\text { Moderately Severe AP } \\
\qquad(n=9)\end{array}$ & $\begin{array}{l}\text { Severe AP } \\
(n=10)\end{array}$ & $p \ddagger$ \\
\hline \multirow{2}{*}{ WBC } & \multirow[t]{2}{*}{$6.5 \pm 1.6$} & Admission & $14.5 \pm 5.4$ & $11.2 \pm 4.5$ & $15.0 \pm 5.6$ & $17.4 \pm 4.1$ & 0.017 \\
\hline & & $48 \mathrm{~h}$ & $12.1 \pm 6.3$ & $6.9 \pm 3.5$ & $12.7 \pm 7.5$ & $14.9 \pm 2.8$ & 0.002 \\
\hline \multirow{2}{*}{ Neutrophils } & \multirow[t]{6}{*}{$4.8 \pm 0.9$} & Admission & $12.4 \pm 5.5$ & $8.6 \pm 4.5$ & $13.2 \pm 5.3$ & $15.7 \pm 3.6$ & 0.011 \\
\hline & & $48 \mathrm{~h}$ & $10.0 \pm 6.2$ & $4.7 \pm 3.2$ & $10.4 \pm 6.9$ & $13.2 \pm 2.7$ & 0.001 \\
\hline \multirow{2}{*}{ SIRI } & & Aission & $7.4 \pm 6.3$ & $3.6 \pm 3.9$ & $8.8 \pm 7.5$ & $11.4 \pm 4.9$ & 0.022 \\
\hline & & $48 \mathrm{~h}$ & $6.6 \pm 6.4$ & $1.6 \pm 2.3$ & $5.9 \pm 6.4$ & $10.6 \pm 5.7$ & 0.001 \\
\hline \multirow{2}{*}{ PCT } & & Admission & $2.9 \pm 6.9$ & $0.7 \pm 0.9$ & $4.5 \pm 5.8$ & $5.9 \pm 10.9$ & 0.001 \\
\hline & & $48 \mathrm{~h}$ & $4.1 \pm 7.3$ & $0.6 \pm 0.1$ & $6.6 \pm 9.1$ & $7.9 \pm 8.8$ & $<0.001$ \\
\hline \multirow{2}{*}{ CRP } & \multirow[t]{2}{*}{$5.3 \pm 1.1$} & Admission & $42.8 \pm 82.7$ & $5.4 \pm 1.2$ & $33.0 \pm 51.5$ & $88.9 \pm 22.0$ & 0.032 \\
\hline & & $48 \mathrm{~h}$ & $170.7 \pm 152.6$ & $15.9 \pm 14.0$ & $180.6 \pm 107.2$ & $316.6 \pm 107.9$ & $<0.001$ \\
\hline \multirow{2}{*}{ Hepcidin } & & Admission & $64.2 \pm 69.6$ & $20.4 \pm 12.2$ & $69.9 \pm 37.9$ & $100.7 \pm 90.5$ & 0.047 \\
\hline & & $48 \mathrm{~h}$ & $136.7 \pm 138.7$ & $26.4 \pm 27.2$ & $56.6 \pm 51.9$ & $286.7 \pm 87.3$ & $<0.001$ \\
\hline \multirow{2}{*}{ Calcium } & & Admission & $9.0 \pm 0.6$ & $8.9 \pm 0.5$ & $9.1 \pm 0.4$ & $8.9 \pm 0.9$ & NS \\
\hline & & $48 \mathrm{~h}$ & $8.5 \pm 0.8$ & $8.9 \pm 0.3$ & $8.7 \pm 0.5$ & $7.9 \pm 1.0$ & 0.014 \\
\hline \multirow[b]{2}{*}{ Albumin } & & Admission & $3.7 \pm 0.5$ & $3.8 \pm 0.4$ & $3.7 \pm 0.4$ & $3.5 \pm 0.5$ & NS \\
\hline & & $48 \mathrm{~h}$ & $3.1 \pm 0.5$ & $3.5 \pm 0.3$ & $3.2 \pm 0.3$ & $2.7 \pm 0.6$ & 0.001 \\
\hline \multirow{2}{*}{ Total proteins } & & Admission & $6.5 \pm 0.6$ & $6.7 \pm 0.5$ & $6.7 \pm 0.5$ & $6.3 \pm 0.6$ & NS \\
\hline & & $48 \mathrm{~h}$ & $5.9 \pm 0.6$ & $6.4 \pm 0.4$ & $6.0 \pm 0.3$ & $5.3 \pm 0.6$ & 0.001 \\
\hline \multirow{2}{*}{ BISAP } & & Admission & $1(1-3)$ & $1(0-1)$ & $1(1-2)$ & $3(2-3)$ & $<0.001$ \\
\hline & & $48 \mathrm{~h}$ & $2(1-4)$ & $1(0-1)$ & $1(1-3)$ & $4(4-5)$ & $<0.001$ \\
\hline \multirow{2}{*}{ SIRS } & & Admission & $1(1-2)$ & $1(0-1)$ & $2(1-2)$ & $2(1-2)$ & 0.045 \\
\hline & & $48 \mathrm{~h}$ & $1(0-2)$ & $0(0-1)$ & $1(0-2)$ & $3(2-3)$ & 0.001 \\
\hline \multirow{2}{*}{ MMS } & & Admission & $0(0-1)$ & $0(0-0)$ & $0(0-2)$ & $1(0-2)$ & 0.017 \\
\hline & & $48 \mathrm{~h}$ & $0(0-2)$ & $0(0-0)$ & $0(0-2)$ & $3(2-3)$ & $<0.001$ \\
\hline
\end{tabular}

AP: acute pancreatitis; BISAP: bedside index for severity in acute pancreatitis; BMI: body mass index; CRP: C-reactive protein; NS: not significant; MMS: modified Marshall score; SIRS: systemic inflammatory response syndrome; WBC: white blood cells.

Through the analysis of Table 2 , both on admission and $48 \mathrm{~h}$ after onset of symptoms, all serological biomarkers except calcium $(p=0.82)$, albumin $(p=0.21)$, and total proteins $(p=0.34)$ on admission show significant changes between the different degrees of AP severity. All the multifactorial scores show significant changes between the degrees of severity of AP.

On admission, PCT (0.83), BISAP (0.83), and SIRI (0.82) had the highest predictive values for severe AP. Regarding mortality, BISAP (0.95), SIRI (0.85), and PCR (0.85) had the highest predictive values. Forty-eight hours after onset of symptoms, for severe AP, the serological marker with the most significant predictive power was hepcidin (1.00) followed by BISAP (0.98), CRP (0.94), and SIRI (0.87). When analyzing the predictive power related to mortality, BISAP (0.94) was found to have the highest predictive value followed by hepcidin (0.90), CRP (0.88), and SIRI (0.86) as represented in Figure 1.

3.2. Patients with Biliary AP Presented Increased Levels of Plasma OS-Related Markers and Lower CAT and SOD Activities Than Healthy Subjects and Increased Levels of Lipid Peroxidation and Lower Levels of CAT and SOD in Severe Biliary AP

As represented in Figure 2A, a significant increase on admission was verified related to the levels of lipid peroxidation $(p<0.05)$, protein nitration $(p<0.001)$, and protein carbonylation $(p<0.05)$ in AP patients when compared with healthy individuals. In addition, as shown in Figure $2 \mathrm{~B}$, there was a significant increase in lipid peroxidation when compared to mild and severe AP $(p<0.05)$ and moderately severe and severe AP $(p<0.05)$. A tendency for increased protein nitration levels in severe AP and in severe forms of AP in protein carbonylation, although without statistical significance, was also demonstrated. 

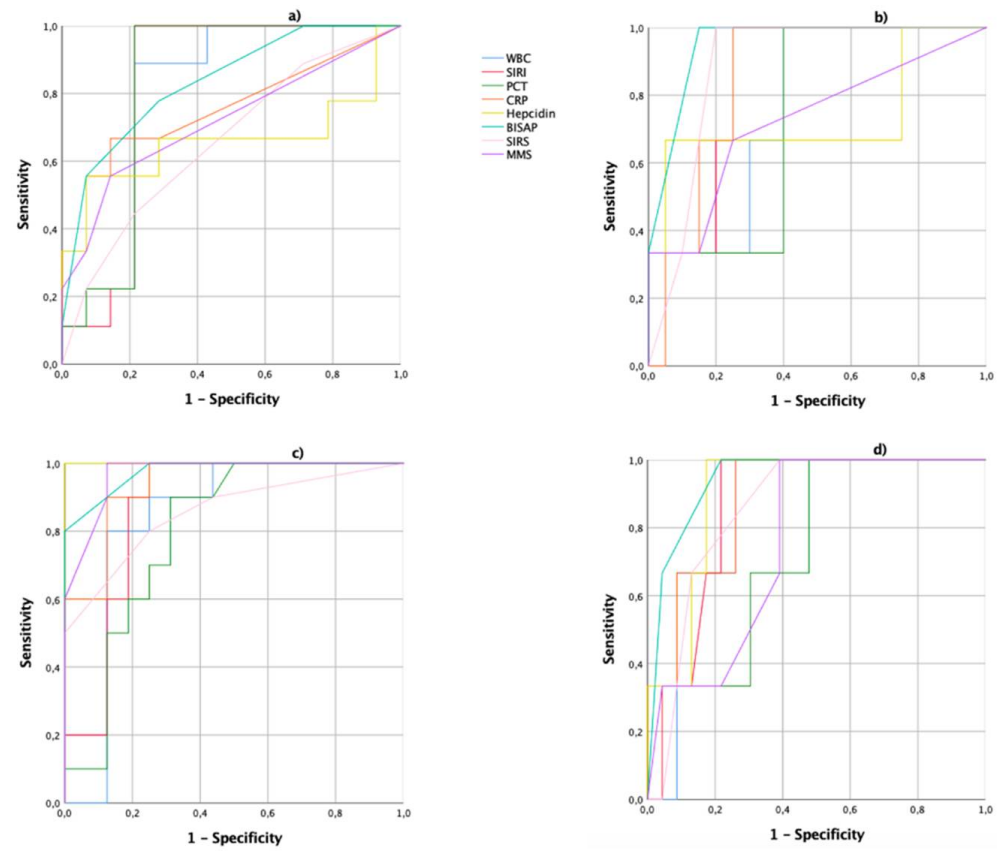

Figure 1. Receiver operating characteristics (ROC) curves for determining the cut-off values of WBC, SIRI, PCT, CRP, hepcidin, BISAP, SIRS, and MMS of (a) severe AP and (b) mortality on admission and (c) severe AP and (d) mortality $48 \mathrm{~h}$ after onset of symptoms. AP: acute pancreatitis; BISAP: bedside index for severity in acute pancreatitis; BMI: body mass index; CRP: C-reactive protein; MMS: modified Marshall score; SIRS: systemic inflammatory response syndrome; WBC: white blood cells.
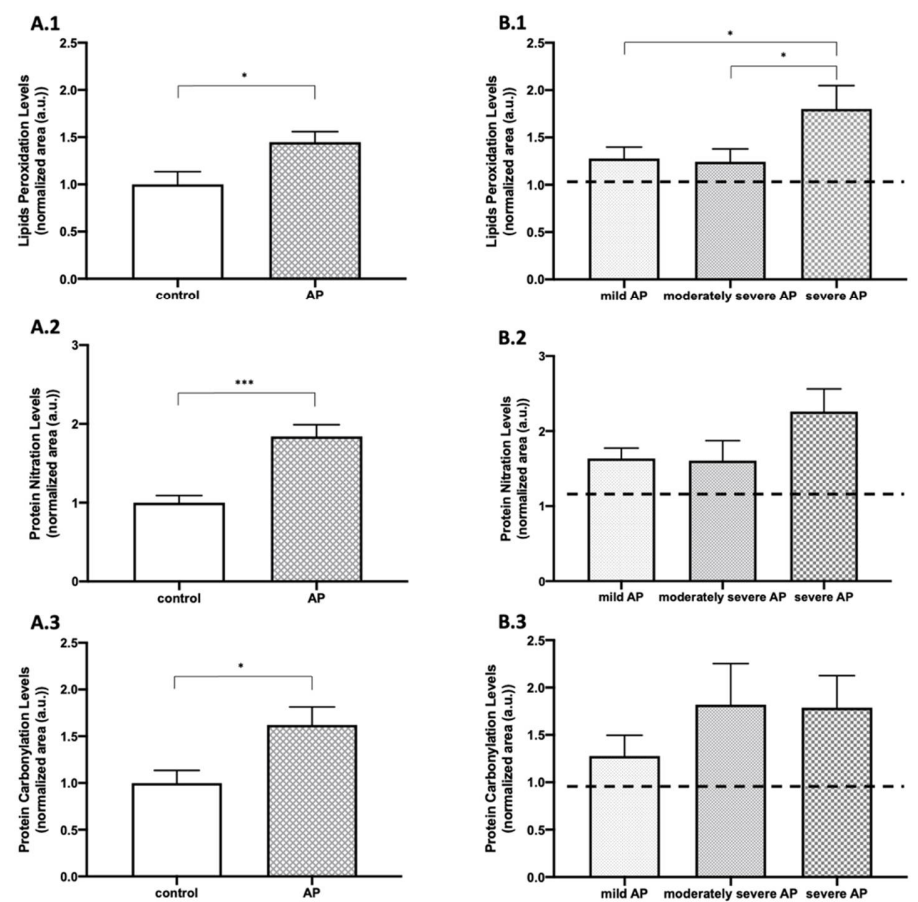

Figure 2. Plasma levels of OS-related markers of acute pancreatitis (AP) and healthy control groups. (A.1) 4-HNE (lipid peroxidation), (A.2) 3-NO (protein nitration), (A.3) DNP (protein carbonylation) in the control group and biliary AP patients. (B.1) 4-HNE (lipid peroxidation), (B.2) 3-NO (protein nitration), (B.3) DNP (protein carbonylation) in the different degrees of biliary AP severity on admission. AP: acute pancreatitis; 3-NO: 3-nitrotyrosine; 4-HNE: 4-hydroxynonenal; DNP: 2,4dinitrophenyl-hydrazone. Results are expressed as mean \pm SEM. The differences versus control are marked by ${ }^{*}$, where ${ }^{*}$ represents $p<0.05$ and ${ }^{* * *} p<0.001$. Mann-Whitney test: (A.1-A.3). Comparison of Fisher's least significant difference post hoc test: (B.1-B.3). 
The activity of enzymes related to the antioxidant system such as GR, GPx, CAT, and SOD were evaluated. As shown in Figure 3A, a tendency toward an increase in GR activity was detected in the plasma of AP patients compared to the healthy control individuals but without statistical significance. CAT and SOD presented with a significant decrease in AP patients' activities compared to the healthy control group $(p<0.01$ and $p<0.001$, respectively).

A.1

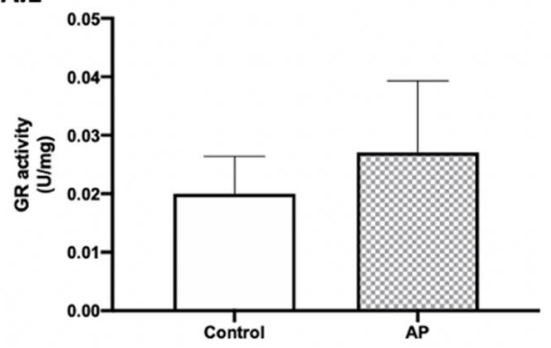

A. 2

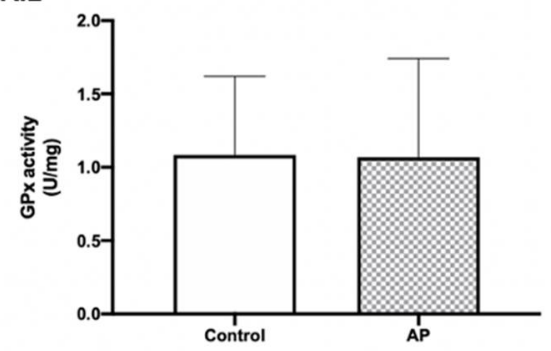

A.3

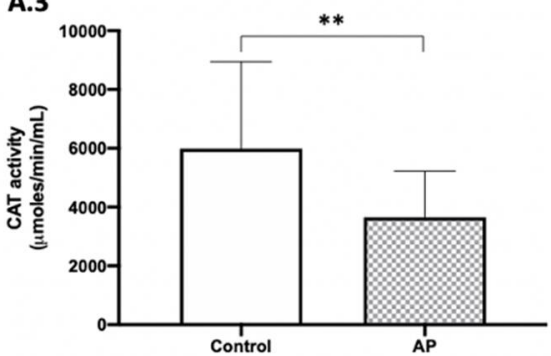

A.4

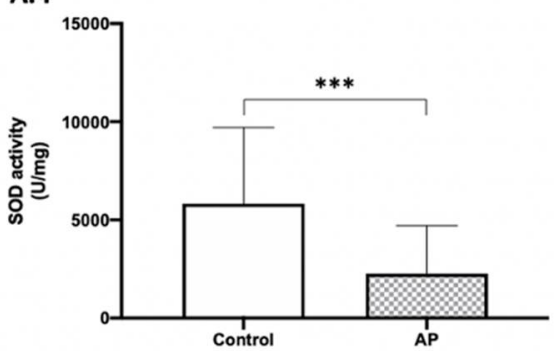

B.1

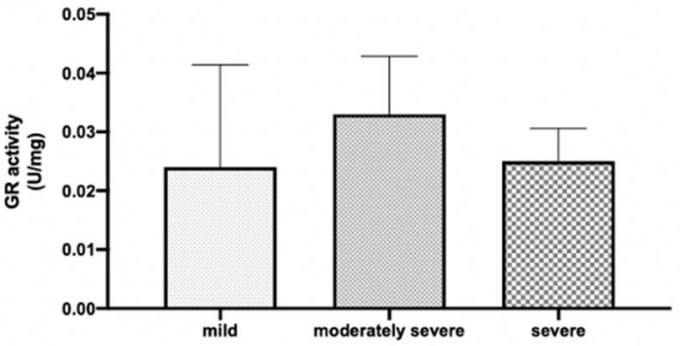

B.2

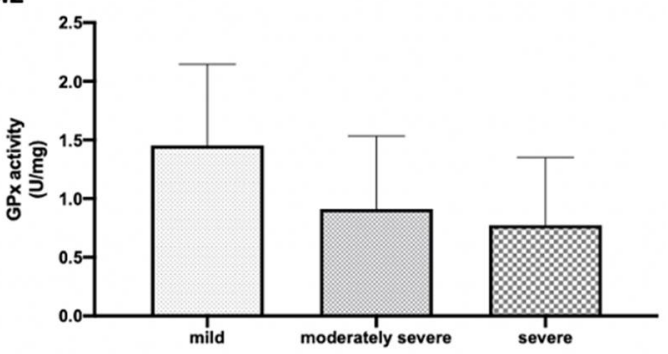

B.3

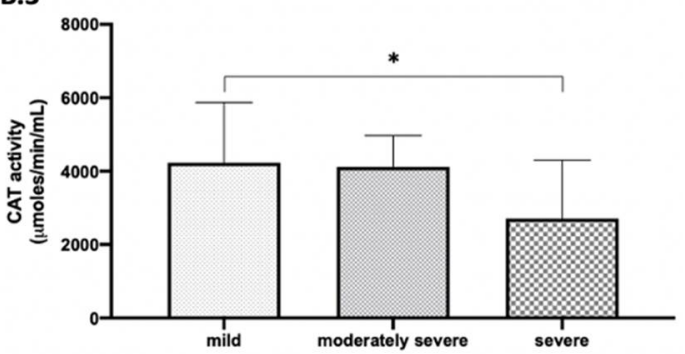

B.4

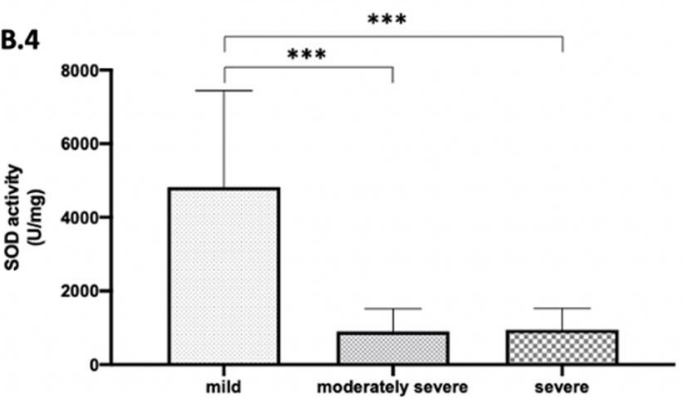

Figure 3. The activity of antioxidant enzymes in plasma of acute pancreatitis (AP) and healthy control groups. GR: glutathione reductase; GPx: glutathione peroxidase; CAT: catalase; SOD: superoxide dismutase from the healthy control group and biliary AP patients (A) and in the different degrees of biliary AP patients $(\mathbf{B})$. Results are expressed as mean \pm SEM. The differences versus control are marked by *, where ${ }^{*}$ represents $p<0.05{ }^{* *} p<0.01$ and ${ }^{* * *} p<0.001$. Mann-Whitney test: (A.1-A.4). Comparison of Fisher's least significant difference post hoc test: (B.1-B.4).

According to the severity, as shown in Figure 3B, when analyzing the activity of the antioxidant enzymes in the plasma of patients with different degrees, there was a 
statistically significant decrease in CAT activity in patients with severe AP compared with mild biliary AP $(p<0.05)$. Plasma SOD activity was also significantly decreased when comparing patients with mild and moderately severe biliary AP and between mild and severe biliary AP patients ( $p<0.001$, for both).

\subsection{NMR-Based Metabonomics Analysis of Plasma Samples from AP Patients}

To analyze the changes in plasma metabolome related to pancreatic inflammation, we applied a nontargeted multivariate analysis. Both exploratory unsupervised method PCA and supervised method PLS-DA scores scatter plots of all severity degrees and analyzed at the same time revealed the significant influence of the inflammatory process on plasma metabolome composition, which can be observed in clustering trends of individual biliary AP groups.

In Figure 4a, PCA was applied to test the internal data structure and search for clustering trends, possible group separation, and outliers. Obtained data demonstrated clustering according to tested groups. Overlap was observed between controls and mild biliary $\mathrm{AP}$ and moderately severe and severe biliary AP, indicating similarities of metabolomes. Additionally, data were analyzed by PLS-DA, as represented in Figure $4 \mathrm{~b}$, which is used to maximize the difference between groups.

a)

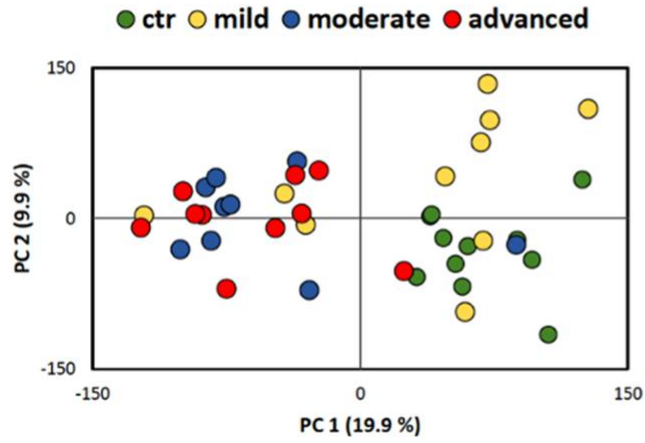

b)

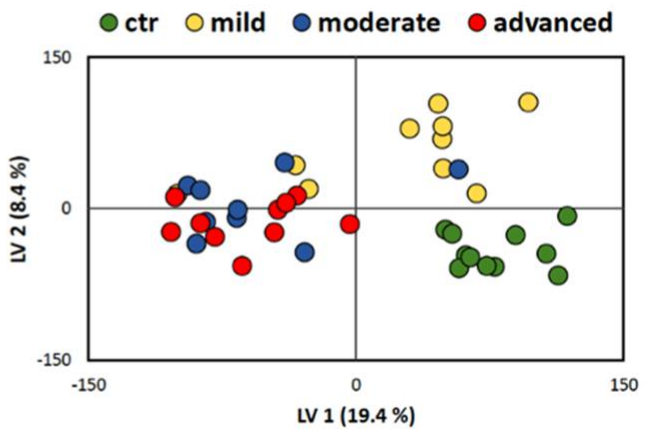

Figure 4. Scores scatter plots obtained via PCA (a) and PLS-DA (b) of 1D cpmg spectra of plasma from healthy control group and biliary AP patients. Degrees of biliary AP severity are indicated in the legends above the plots.

Pair-wise comparisons between biliary AP severity degrees and the healthy control group were performed (PCA and PLS-DA) to identify the metabolites contributing to group separation. In PCA scores, scatter plot clustering according to tested groups and precise separation between the groups can be observed in Figure 5a. PLS-DA analysis further confirmed the groups' separations. A sevenfold internal cross-validation was applied to assess the explained variance $\left(\mathrm{R}^{2}\right)$ and predicative power $\left(\mathrm{Q}^{2}\right)$ of PLS-DA models, as represented in Figure $5 \mathrm{~b}$. Although the internal validation yielded satisfactory model parameters, additional validation was performed via the permutation test.

The PLS-DA quality assessment parameters, goodness of fit to the data $R^{2}$, and predictive value of the model $\mathrm{Q}^{2}$ were $>0.8$ in all the constructed models and corroborate model reliability and their suitability for data mining, as represented in Figure $5 \mathrm{c}$. The results can also be presented as a heatmap (Figure 6) of biologically relevant effect sizes (ES > 0.7) [44] concerning the results attained in the plasma of the group of patients with biliary AP severity (mild, moderately severe, or severe) when compared with the healthy control group. This representation shows that plasma valine levels had an inferior difference between healthy and mild biliary AP, but it was gradually increased from moderately severe and severe AP. The same happens to isoleucine, threonine, histidine, and lipids contents. When phenylalanine was analyzed, there was a marked increase in healthy and severe AP levels. In turn, malate showed a marked increase between healthy and moderately severe AP patients. 
a)

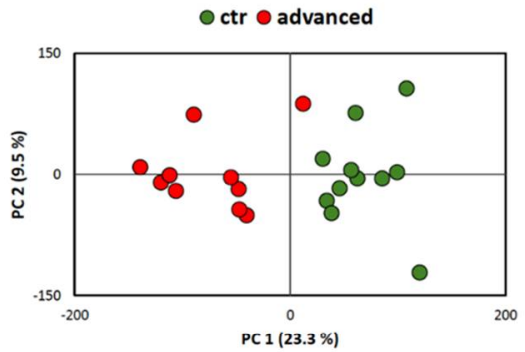

b)

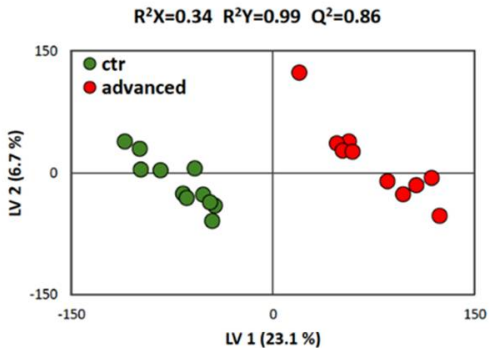

c)

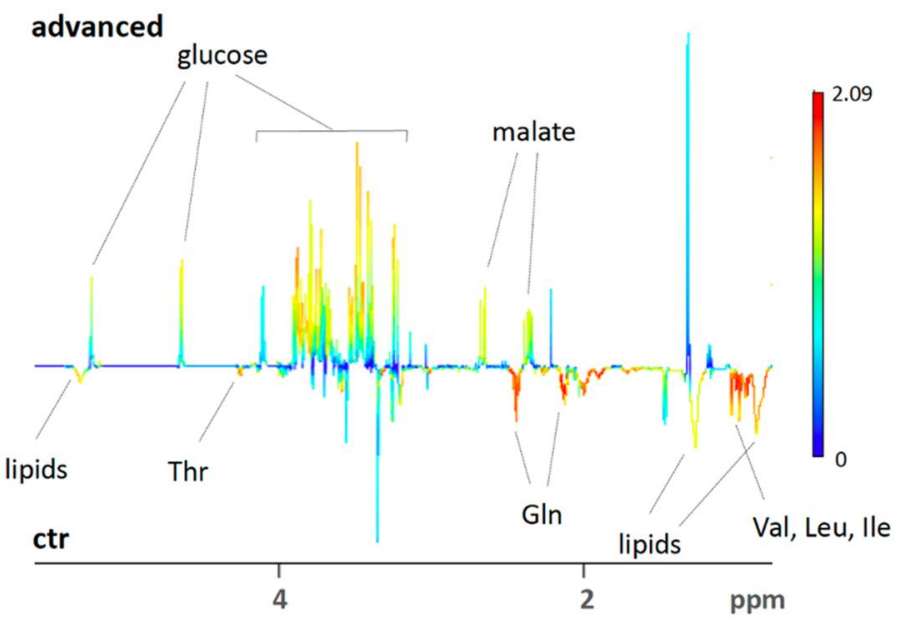

Figure 5. Scores scatter plots obtained via PCA (a) and PLS-DA (b) of 1D cpmg spectra of plasma from healthy control group and severe biliary AP patients. LV1 loadings extracted from PLS-DA are presented in (c). Loadings are colored according to variable importance of the projection (VIP), and some assignments are indicated.

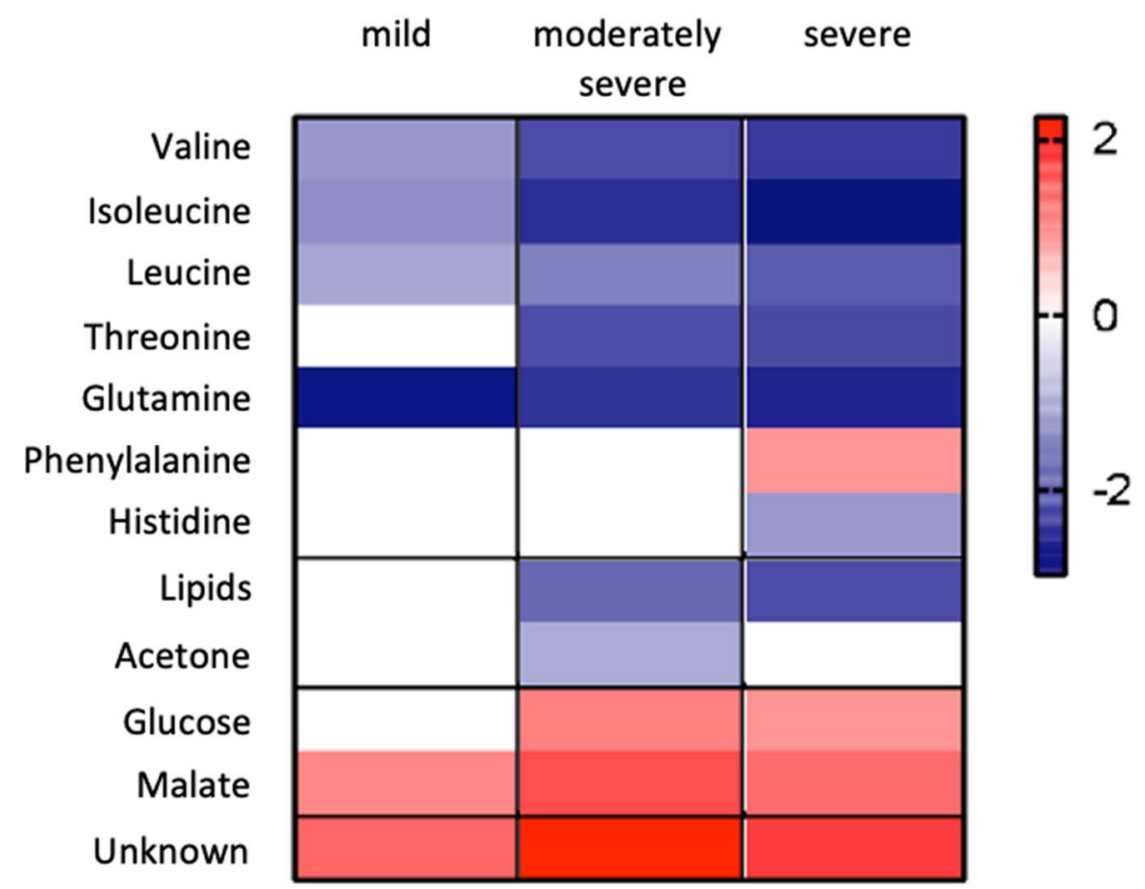

Figure 6. Heatmap of effect sizes representing plasma metabolome changes associated with severe biliary AP patients as compared with healthy control group. 


\subsection{Plasma Metabolic Profiles Show Differential Response to AP Diagnosis and Prognosis}

The plasma metabolome seems to be highly sensitive to the diagnosis of AP. Among the different metabolites expressed in both groups, healthy control and biliary AP patients, were valine $(0.009 \pm 0.001$ vs. $0.001 \pm 0.002, p<0.001)$, isoleucine $(0.004 \pm 0.001$ vs. $0.003 \pm 0.001, p<0.001)$, leucine $(0.005 \pm 0.001$ vs. $0.004 \pm 0.001, p<0.001)$, threonine $(0.003 \pm 0.0004$ vs. $0.002 \pm 0.001, p<0.001)$, glutamine $(0.012 \pm 0.002$ vs. $0.006 \pm 0.003$, $p<0.001)$, glucose $(0.006 \pm 0.002$ vs. $0.007 \pm 0.001, p<0.05)$, malate $(0.001 \pm 0.0004$ vs. $0.004 \pm 0.003, p<0.01)$, lipids $(0.069 \pm 0.01$ vs. $0.054 \pm 0.02, p<0.05$ and $0.013 \pm 0.004$ vs. $0.01 \pm 0.007, p<0.05)$, and acetone $(0.021 \pm 0.005$ vs. $0.015 \pm 0.01, p<0.05)$, as represented in Figure 7.
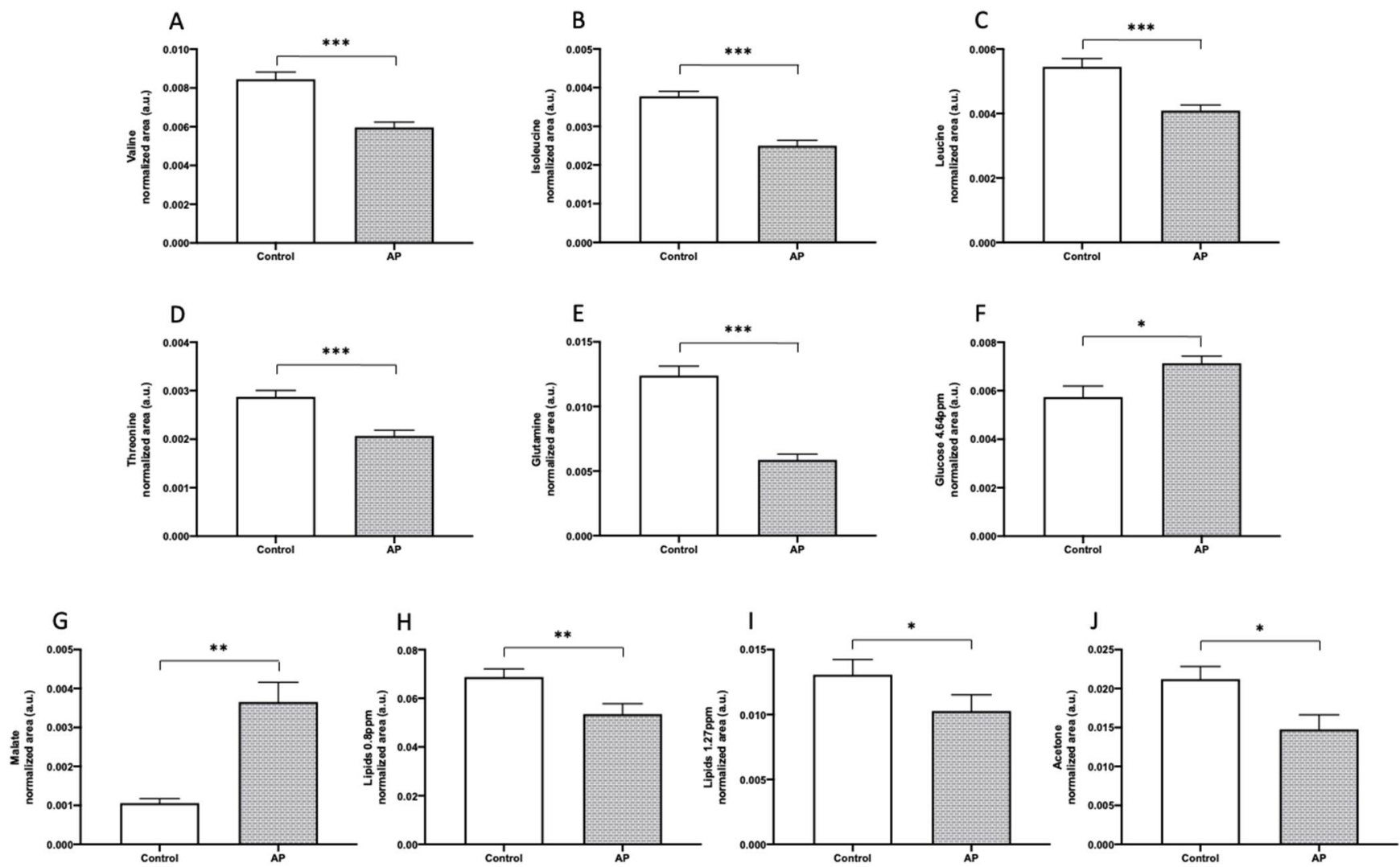

Figure 7. The quantitative abundance of different metabolites in the plasma of healthy control group and biliary AP patients. Results are expressed as mean \pm SEM. The differences versus control are marked by ${ }^{*}$, where * represents $p<0.05,{ }^{* *} p<0.01$ and ${ }^{* * *} p<0.001$. Student's $t$ test: $(\mathbf{A}-\mathbf{D}, \mathbf{F}, \mathbf{H}, \mathbf{J})$; Mann-Whitney test: $(\mathbf{E}, \mathbf{G}, \mathbf{I})$.

When plasma metabolomes were analyzed for AP prognosis, it was found that threonine (mild: $0.002 \pm 0.001$ vs. moderately severe: $0.002 \pm 0.001, p<0.05$ ), phenylalanine (mild: $0.002 \pm 0.001$ vs. severe: $0.004 \pm 0.001, p<0.05$ ), and lipids content (mild: $0.071 \pm 0.028$ vs. moderately severe: $0.046 \pm 0.001, p<0.05$; mild: $0.071 \pm 0.028$ vs. severe: $0.054 \pm 0.02, p<0.01$ and mild: $0.015 \pm 0.009$ vs. moderately severe: $0.008 \pm 0.003, p<0.01$; mild: $0.015 \pm 0.009$ vs. severe: $0.01 \pm 0.007, p<0.01$ ) showed changes with statistical significance, as represented in Figure 8. 

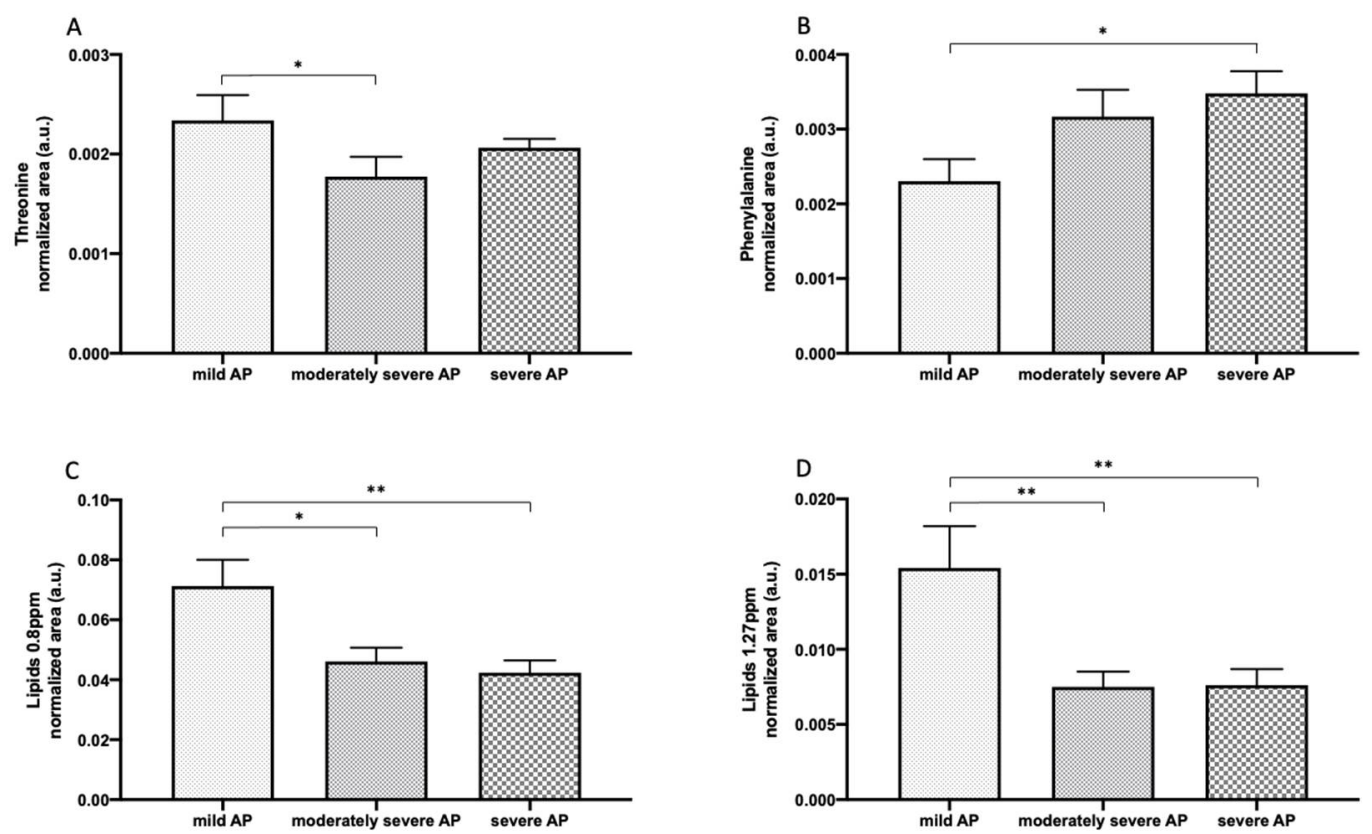

Figure 8. The quantitative abundance of different metabolites in the plasma of different degrees of biliary AP severity. Results are expressed as mean \pm SEM. The differences versus control are marked by ${ }^{*}$, where ${ }^{*}$ represents $p<0.05$ and ${ }^{* *} p<0.01$. Comparison of Fisher's least significant difference post hoc test: $(\mathbf{A}-\mathbf{C})$; Comparison of the Tukey's post hoc test: (D).

\section{Discussion}

AP is an inflammatory disorder of the pancreas, responsible for many hospital admissions and associated with enormous economic cost $[45,46]$. In this sense, the stratification of the severity of AP is crucial not only for obtaining good clinical outcomes but also cost-effectiveness. The severity of AP can be predicted based upon clinical, laboratory, and radiologic risk factors, several score systems, and biomarkers. However, the complex mechanism of AP and its association with a progressive SIRS with high morbidity and mortality is not fully understood, and robust prognostic biomarkers are necessary $[47,48]$. Unfortunately, none has yet proven to be an excellent accurate predictor of the clinical course of AP. Gallstones are the leading cause of AP and result from the impaction of migratory gallstones in the ampulla. The population included in this study was exclusively composed of patients with biliary AP, considered the most common etiology in Mediterranean countries [8]. There are few studies aimed at this subtype of the patient population [49]. Currently, the diagnosis of AP is based on the RAC criteria that consider clinical, laboratory, and imaging factors [17]. The prognosis is based on several serological biomarkers and multifactorial scores. However, there is no specific prognostic tool for AP [13]. In this study, several serological biomarkers and multifactorial scores were analyzed. The times evaluated were on admission, considered the ideal time for assessment of prognosis, and $48 \mathrm{~h}$ after onset of symptoms to analyze the predictive power of the different markers when persistent organ failure was defined. Therefore, on admission, when the severity was assessed, it was found that the serological markers that had the most significant power were PCT and SIRI. When mortality was assessed, it was found that SIRI and CRP had the best predictive value. When severity and mortality were assessed $48 \mathrm{~h}$ after the onset of symptoms, it was found that hepcidin, CRP, and SIRI had the most significant predictive value.

PCT, a 116-amino-acid pro-peptide of calcitonin, was found to appear in high concentration during inflammation and sepsis, being released by hepatocytes, peripheral monocytes, and C-cells of the thyroid gland [50,51]. Increased PCT levels had been observed in severe AP, pancreatitis necrosis, and organ failure [46]. In the present study, on admission, PCT showed a better predictive value of severe AP (0.825). 
SIRI was first described for the study of cancer-related inflammation [52]. This index lists the levels of neutrophils, monocytes, and lymphocytes in the blood count of cancer patients and their prognosis and in assessing the response of chemotherapy (QT) regimens [52,53]. Previous work demonstrated that this ratio also correlated with the severity of $\mathrm{AP}$, and for the cut-off of 7.14, the sensitivity, specificity, and accuracy were $82 \%, 87 \%$, and $85 \%$, respectively. In the present study, this ratio proved to have good predictive power for the severity and mortality of AP on admission and $48 \mathrm{~h}$ after onset of symptoms.

CRP is an acute-phase protein synthesized by the liver, induced by cytokines like IL-6, and its level in the blood increases within hours in response to inflammation and sepsis. It was described as a predictive tool for AP prognosis and mortality [46]. This acute-phase reactant has been widely used as an independent predictor of AP severity and mortality, especially $48 \mathrm{~h}$ after hospital admission [54]. The same was verified in this study, showing an excellent predictive power for severity $48 \mathrm{~h}$ after the onset of symptoms. Upon admission, it proved to be a good predictor of mortality related to AP.

Hepcidin is a peptide hormone responsible for regulating the hemostasis of iron, which is the primary source of the synthesis of hepcidin in the liver. Extra-hepatic production of hepcidin was described in the heart, kidneys, retina, monocytes, and macrophages, alveolar cells, adipocytes, pancreatic $\beta$-cells, and bile [55]. The hepcidin levels increase during inflammation, primarily as a result of increased IL-6 and -1 [56]. Since hepcidin is also synthesized in the pancreas and biliary system, we can state that it predicts specific and nonspecific inflammation of AP, making it a unique biomarker. In the present study, as we showed in our previous study [13], hepcidin showed the best predictive power for both severity and mortality $48 \mathrm{~h}$ after onset of symptoms.

In the early events of $\mathrm{AP}$, OS plays a pivotal role since ROS cause direct oxidative damage to lipids and proteins and modulate redox-sensitive transcription factors and redox-sensitive signal transduction pathways [57]. OS appears to have a relevant role in the initial phase of AP. Once produced, ROS can act as a molecular trigger for the pancreatic inflammatory process [58]. They also play a central role in perpetuating this process, leading to the progression of extrapancreatic complications [57,58]. In this study, on admission, plasma lipid peroxidation, protein nitration, and protein carbonylation were increased in biliary AP patients compared to the healthy control group. These results provided further evidence of the role of OS as a mediator in the initial phase of the pancreatic inflammatory process. The lipid peroxidation may be associated with primary cytosolic granules within polymorphonucleocytes and the inflammatory process [59]. Products of lipid peroxidation also may, in turn, be associated with damage of membrane integrity, inactivation of membrane-bound receptors, and enzymes, resulting in cell damage. These lipid peroxidation products, especially 4-HNE, react with proteins, changing their conformation and function, leading to enhanced inflammatory response [60]. Furthermore, OS-related markers of damage in proteins and lipids were studied in the plasma of patients with different degrees of biliary AP severity. The obtained data show statistically differences in the levels of lipid peroxidation between mild and severe biliary AP and moderately severe and severe biliary AP and no statistically relevant differences in protein nitration and protein carbonylation levels between the different degrees of biliary AP severity. However, it is essential to note that the small sample analyzed may influence these results and that a larger sample may show other results, namely statistical significance.

The inflammatory process in the pancreas has also been associated with a decline in antioxidant defenses, including GR, GPx, CAT, and SOD activities [61]. In the present study, CAT and SOD activities were significantly decreased in the plasma of patients with AP compared with the healthy control group. These enzymes are components of the cellular antioxidant enzyme system that detoxifies hydrogen peroxide and organic peroxides. Free radicals produced by active leukocytes may oxidize the active sites of these enzymes, thereby causing reduced activity. Of note, CAT and SOD showed decreases in plasma concentration of patients with different degrees of biliary AP severity. CAT activity in the plasma was further decreased in patients with severe biliary AP compared with those with 
mild biliary AP. SOD activity was also decreased in the plasma of patients with severe biliary AP. These findings are consistent with previous studies, which reported a decrease in antioxidant enzymes' expression in murine models and patients with AP $[62,63]$. In addition, the decrease of antioxidant defenses may explain the increase in lipid peroxidation among patients with severe biliary AP. Thus, the obtained data further support that the different degrees of AP severity are associated with different degrees of OS-related effects, being that severe AP induces major lipid peroxidation as detected in the plasma. Thus, those patients present a lower antioxidant capacity presented as decreased activity of antioxidant enzymes. However, further studies will be needed to unveil whether that is a cause or a consequence of severe AP.

Metabonomics is a rapid and noninvasive analysis that consists of the systematic study of metabolites as small-molecule biomarkers that represent the functional phenotype in a cell, tissue or organism [64]. The obtained data suggested metabolic dysfunction, and, thus, we applied a metabonomic-based NMR study to metabolically characterize the plasma of patients with different degrees of biliary AP severity. On admission, valine, isoleucine, leucine, threonine, glutamine, glucose, malate, and acetone were significantly altered in AP patients' plasma compared with the healthy control group, highlighting that, patients with AP present a systemic alteration in their metabolic profile. Regarding the prognosis of biliary AP severity, threonine and phenylalanine showed changes in the plasma of patients with mild and moderately severe biliary AP and mild and severe biliary $\mathrm{AP}$, respectively, while lipids content was changed in the plasma of patients with mild and moderately severe biliary AP and mild and severe AP. These findings demonstrate that biliary AP causes evident disruption of pancreatic metabolism at a molecular level, and these metabolites could be potential markers for the diagnosis or onset and prognosis of biliary AP. The characterization of the metabonomic profile in the present study allowed for the identification of metabolites affected by biliary AP severity.

Branched-chain amino acids signals (valine, leucine, and isoleucine) were decreased in the plasma of patients with biliary AP compared to the control group. This observation was also described by Villaseñor et al. [27]. It is very relevant because these amino acids are a component of pancreatic juice, and the decrease in their concentration in circulation may be related to the exocrine pancreatic insufficiency characteristics of severe AP [65]. Thus, they should be regarded as potential biomarkers for the onset and with the potential to determine the progression of $\mathrm{AP}$, but more studies will be needed to validate these hypotheses.

Glutamine is a crucial element in the tricarboxylic acid cycle [66]. During catabolic stress, namely sepsis, its levels rapidly decrease [67]. Glutamine is also important since it maintains gut barrier function [68], which prevents the progression of inflammation and infection in AP. In this study, plasma glutamine concentration was decreased in the patients with biliary AP, suggesting that it inhibits the metabolization of this substrate by repressing the metabolization of glutamine at some level. Since the gut barrier can be affected, there may be a progression of the inflammatory process, namely in the necrosis infection verified in the severe AP.

Malate concentration in the plasma was also altered when comparing to the healthy control group to biliary AP patients. This metabolite is a product of carbohydrate breakdown through the tricarboxylic acid cycle to provide additional energy in the form of adenosine phosphate [69]. The increase in plasma concentration of malate detected in biliary AP patients suggests an increased demand for energy due to the severe acute pancreatic and systemic inflammatory process. This study demonstrated an increase of malate in the plasma of patients with all degrees of biliary AP severity, suggesting a possible involvement of the tricarboxylic acid cycle in the inflammatory process mediated by the onset of biliary AP.

In this study, low plasma levels of threonine were found in patients with biliary AP compared to the healthy control group and in moderately severe biliary AP patients when compared with mild biliary AP patients. Low levels of threonine are associated with changes in inflammatory cytokines [70]. This action is more accentuated in the intestinal 
immune response. In AP, changes in intestinal immunity may be associated with bacterial translocation and the presence of secondary pancreatic infection, which occurs mainly in the severe form of AP.

Phenylalanine is an amino acid strongly associated with mortality in patients with severe infection since high levels are related to severe metabolic disturbance [71]. In this study, the plasma levels of phenylalanine were higher in the patients with severe biliary AP than the levels detected in patients with mild biliary AP. Phenylalanine is one of the essential amino acids that can be oxidized into tyrosine via hydroxylase catalysis and together with tyrosine to synthesize important neurotransmitters and hormones. Overall, taking into consideration our data, this amino acid may be considered as a prognostic marker for severe biliary AP.

Lipid metabolism can cause OS reaction and acidosis, leading to injury of the pancreas, surrounding tissues, and hypoxic necrosis, features of the severe form of AP [72]. AP could lead to abnormal lipid metabolism under the regulation of nerves and body fluids [73].

This study had several limitations that must be considered when interpreting the data. The most important being the relatively small number of patients. However, we detected crucial changes in the metabonomics and OS analyses of plasma of patients with different degrees of biliary AP severity. Some may be used as biomarkers for the onset and progression of AP but need further validation with a higher number of samples.

\section{Conclusions}

This study allowed us to confirm the role of hepcidin and SIRI as new prognostic biomarkers of biliary AP. Overall, our results confirmed that OS has a role in the onset and progression of the pancreatic inflammatory process. This study also constituted the first metabonomic study in the field of biliary AP, and it allowed us to show that metabonomics can be fundamental for understanding the pathophysiology of AP. We identified molecular mechanisms associated with metabolic and OS profiles that may predict the onset and progression of biliary AP severity. This study may help identify and better understand mechanisms underlying the pancreatic inflammatory process, allowing for the eventual development of new and relevant target therapies.

Author Contributions: Conceptualization: P.S.-V., J.G.T., M.G.A. and A.M.A.; methodology: P.S.-V., M.G.A. and A.M.A.; data curation: P.S.-V. and A.M.A.; investigation: P.S.-V., I.J., L.R., P.F.O., M.G.A. and A.M.A.; formal analysis: P.S.-V., I.J., S.M.-N., M.G.A. and A.M.A.; writing-original draft: P.S.-V. and A.M.A.; writing-review and editing: A.P., M.C.-B., M.F.B., J.G.T., M.G.A. and A.M.A. All authors have read and agreed to the published version of the manuscript.

Funding: This work was supported by the Foundation for Science and Technology (FCT), Portugal through financial support (Strategic Projects UID/NEU/04539/2019, UIDB/04539/2020 and UIDP/04539/2020 (CIBB) and FCT: M.G.Alves (IFCT2015), UMIB (UIDB/00215/2020 and UIDP/00215/2020); NMR data was collected at the UC-NMR facility which is supported in part by FEDER-European Regional Development Fund through the COMPETE Programme (Operational Programme for Competitiveness) and by National Funds through FCT through grants REEQ/481/QUI/2006, RECI/QEQ-QFI/0168/2012, CENTRO-07-CT62-FEDER-002012, and Rede Nacional de Ressonância Magnética Nuclear (RNRMN).

Institutional Review Board Statement: The study was conducted according to the guidelines of the Declaration of Helsinki and approved by the Ethics Committee of the Hospital Amato Lusitano of Unidade Local de Saúde de Castelo Branco (10294/15 and 8 June 2015).

Informed Consent Statement: Informed consent was obtained from all subjects involved in the study.

Data Availability Statement: All generated data in this study are included in the article.

Acknowledgments: We thank to the Department of Clinical Pathology at the Hospital Amato Lusitano, Unidade Local de Saúde de Castelo Branco for all the support in this study.

Conflicts of Interest: The authors declare no conflict of interest. 


\section{References}

1. Kaplan, M.; Ates, I.; Akpinar, M.Y.; Yuksel, M.; Kuzu, U.B.; Kacar, S.; Coskun, O.; Kayacetin, E. Predictive value of C-reactive protein/albumin ratio in acute pancreatitis. Hepatobiliary Pancreat. Dis. Int. 2017, 16, 424-430. [CrossRef]

2. Lu, J.D.; Cao, F.; Ding, Y.X.; Wu, Y.D.; Guo, Y.L.; Li, F. Timing, distribution, and microbiology of infectious complications after necrotizing pancreatitis. World J. Gastroenterol. 2019, 25, 5162-5173. [CrossRef] [PubMed]

3. Singh, V.K.; Bollen, T.L.; Wu, B.U.; Repas, K.; Maurer, R.; Yu, S.; Mortele, K.J.; Conwell, D.L.; Banks, P.A. An assessment of the severity of interstitial pancreatitis. Clin. Gastroenterol. Hepatol. 2011, 9, 1098-1103. [CrossRef] [PubMed]

4. Kim, M.-J.; Bae, G.-S.; Jo, I.-J.; Choi, S.-B.; Kim, D.-G.; Jung, H.-J.; Song, H.-J.; Park, S.-J. Fraxinellone inhibits inflammatory cell infiltration during acute pancreatitis by suppressing inflammasome activation. Int. Immunopharmacol. 2019, 69, 169-177. [CrossRef] [PubMed]

5. Hagjer, S.; Kumar, N. Evaluation of the BISAP scoring system in prognostication of acute pancreatitis-A prospective observational study. Int. J. Surg. 2018, 54, 76-81. [CrossRef] [PubMed]

6. Samanta, J.; Dhaka, N.; Gupta, P.; Singh, A.K.; Yadav, T.D.; Gupta, V.; Sinha, S.K.; Kochhar, R. Comparative study of the outcome between alcohol and gallstone pancreatitis in a high-volume tertiary care center. JGH Open 2019, 3, 338-343. [CrossRef] [PubMed]

7. Silva-Vaz, P.; Abrantes, A.M.; Castelo-Branco, M.; Gouveia, A.; Botelho, M.F.; Tralhão, J.G. Murine Models of Acute Pancreatitis: A Critical Appraisal of Clinical Relevance. Int. J. Mol. Sci. 2019, 20, 2794. [CrossRef] [PubMed]

8. Roberts, S.E.; Morrison-Rees, S.; John, A.; Williams, J.G.; Brown, T.H.; Samuel, D.G. The incidence and aetiology of acute pancreatitis across Europe. Pancreatology 2017, 17, 155-165. [CrossRef] [PubMed]

9. Wang, G.J.; Gao, C.F.; Wei, D.; Wang, C.; Ding, S.Q. Acute pancreatitis: Etiology and common pathogenesis. World J. Gastroenterol. 2009, 15, 1427-1430. [CrossRef] [PubMed]

10. Saluja, A.; Dudeja, V.; Dawra, R.; Sah, R.P. Early Intra-Acinar Events in Pathogenesis of Pancreatitis. Gastroenterology 2019, 156, 1979-1993. [CrossRef] [PubMed]

11. Mayer, A.; McMahon, M.; Bowen, M.; Cooper, E. C reactive protein: An aid to assessment and monitoring of acute pancreatitis. J. Clin. Pathol. 1984, 37, 207-211. [CrossRef] [PubMed]

12. Arabul, M.; Celik, M.; Aslan, O.; Torun, S.; Beyazit, Y.; Alper, E.; Kandemir, A.; Ünsal, B. Hepcidin as a predictor of disease severity in acute pancreatitis: A single center prospective study. Hepatogastroenterology 2013, 60, 595-600. [PubMed]

13. Silva-Vaz, P.; Abrantes, A.M.; Morgado-Nunes, S.; Castelo-Branco, M.; Gouveia, A.; Botelho, M.F.; Tralhão, J.G. Evaluation of Prognostic Factors of Severity in Acute Biliary Pancreatitis. Int. J. Mol. Sci. 2020, 21, 4300. [CrossRef] [PubMed]

14. Woo, S.M.; Noh, M.H.; Kim, B.G.; Hsing, C.T.; Han, J.S.; Ryu, S.H.; Seo, J.M.; Yoon, H.A.; Jang, J.S.; Choi, S.R.; et al. Comparison of serum procalcitonin with Ranson, APACHE-II, Glasgow and Balthazar CT severity index scores in predicting severity of acute pancreatitis. Korean J. Gastroenterol. Taehan Sohwagi Hakhoe Chi 2011, 58, 31-37. [CrossRef] [PubMed]

15. Wu, B.U.; Johannes, R.S.; Sun, X.; Tabak, Y.; Conwell, D.L.; Banks, P.A. The early prediction of mortality in acute pancreatitis: A large population-based study. Gut 2008, 57, 1698-1703. [CrossRef] [PubMed]

16. Mofidi, R.; Duff, M.; Wigmore, S.; Madhavan, K.; Garden, O.; Parks, R. Association between early systemic inflammatory response, severity of multiorgan dysfunction and death in acute pancreatitis. Br. J. Surg. 2006, 93, 738-744. [CrossRef] [PubMed]

17. Banks, P.A.; Bollen, T.L.; Dervenis, C.; Gooszen, H.G.; Johnson, C.D.; Sarr, M.G.; Tsiotos, G.G.; Vege, S.S. Classification of acute pancreatitis-2012: Revision of the Atlanta classification and definitions by international consensus. Gut 2013, 62, $102-111$. [CrossRef] [PubMed]

18. Criddle, D.N. Reactive oxygen species, $\mathrm{Ca}(2+)$ stores and acute pancreatitis; a step closer to therapy? Cell Calcium 2016, 60 , 180-189. [CrossRef] [PubMed]

19. Park, B.K.; Chung, J.B.; Lee, J.H.; Suh, J.H.; Park, S.W.; Song, S.Y.; Kim, H.; Kim, K.H.; Kang, J.K. Role of oxygen free radicals in patients with acute pancreatitis. World J. Gastroenterol. 2003, 9, 2266-2269. [CrossRef] [PubMed]

20. Closa, D. Free radicals and acute pancreatitis: Much ado about...something. Free Radic. Res. 2013, 47, 934-940. [CrossRef] [PubMed]

21. Booth, D.M.; Mukherjee, R.; Sutton, R.; Criddle, D.N. Calcium and reactive oxygen species in acute pancreatitis: Friend or foe? Antioxid. Redox Signal. 2011, 15, 2683-2698. [CrossRef] [PubMed]

22. Que, R.S.; Cao, L.P.; Ding, G.P.; Hu, J.A.; Mao, K.J.; Wang, G.F. Correlation of nitric oxide and other free radicals with the severity of acute pancreatitis and complicated systemic inflammatory response syndrome. Pancreas 2010, 39, 536-540. [CrossRef] [PubMed]

23. Vayssier-Taussat, M.; Kreps, S.E.; Adrie, C.; Dall'Ava, J.; Christiani, D.; Polla, B.S. Mitochondrial membrane potential: A novel biomarker of oxidative environmental stress. Environ. Health Perspect. 2002, 110, 301-305. [CrossRef] [PubMed]

24. Trumbeckaite, S.; Kuliaviene, I.; Deduchovas, O.; Kincius, M.; Baniene, R.; Virketyte, S.; Bukauskas, D.; Jansen, E.; Kupcinskas, L.; Borutaite, V.; et al. Experimental acute pancreatitis induces mitochondrial dysfunction in rat pancreas, kidney and lungs but not in liver. Pancreatology 2013, 13, 216-224. [CrossRef] [PubMed]

25. Rau, B.; Poch, B.; Gansauge, F.; Bauer, A.; Nüssler, A.K.; Nevalainen, T.; Schoenberg, M.H.; Beger, H.G. Pathophysiologic role of oxygen free radicals in acute pancreatitis: Initiating event or mediator of tissue damage? Ann. Surg. 2000, 231, 352-360. [CrossRef] [PubMed]

26. Gu, W.; Tong, Z. Clinical Application of Metabolomics in Pancreatic Diseases: A Mini-Review. Lab. Med. 2020, 51, 116-121. [CrossRef] [PubMed] 
27. Villasenor, A.; Kinross, J.M.; Li, J.V.; Penney, N.; Barton, R.H.; Nicholson, J.K.; Darzi, A.; Barbas, C.; Holmes, E. 1H NMR global metabolic phenotyping of acute pancreatitis in the emergency unit. J. Proteome Res. 2014, 13, 5362-5375. [CrossRef] [PubMed]

28. Lusczek, E.R.; Paulo, J.A.; Saltzman, J.R.; Kadiyala, V.; Banks, P.A.; Beilman, G.; Conwell, D.L. Urinary 1H-NMR metabolomics can distinguish pancreatitis patients from healthy controls. JOP J. Pancreas 2013, 14, 161-170.

29. Xu, H.; Zhang, L.; Kang, H.; Zhang, J.; Liu, J.; Liu, S. Serum Metabonomics of Mild Acute Pancreatitis. J. Clin. Lab. Anal. 2016, 30, 990-998. [CrossRef] [PubMed]

30. Xiao, H.; Huang, J.-h.; Zhang, X.-w.; Ahmed, R.; Xie, Q.-1.; Li, B.; Zhu, Y.-m.; Cai, X.; Peng, Q.-h.; Qin, Y.-h. Identification of potential diagnostic biomarkers of acute pancreatitis by serum metabolomic profiles. Pancreatology 2017, 17, 543-549. [CrossRef] [PubMed]

31. Huang, J.H.; He, D.; Chen, L.; Dong, C.Y.; Zhang, S.H.; Qin, Y.H.; Yu, R.; Ahmed, R.; Kuang, J.J.; Zhang, X.W. GC-MS based metabolomics strategy to distinguish three types of acute pancreatitis. Pancreatology 2019, 19, 630-637. [CrossRef] [PubMed]

32. Weitz, G.; Woitalla, J.; Wellhöner, P.; Schmidt, K.J.; Büning, J.; Fellermann, K. Comorbidity in acute pancreatitis relates to organ failure but not to local complications. Z. Gastroenterol. 2016, 54, 226-230. [CrossRef] [PubMed]

33. Brusselaers, N.; Lagergren, J. The Charlson Comorbidity Index in Registry-based Research. Methods Inf. Med. 2017, 56, 401-406. [PubMed]

34. Dias, T.R.; Alves, M.G.; Bernardino, R.L.; Martins, A.D.; Moreira, A.C.; Silva, J.; Barros, A.; Sousa, M.; Silva, B.M.; Oliveira, P.F. Dose-dependent effects of caffeine in human Sertoli cells metabolism and oxidative profile: Relevance for male fertility. Toxicology 2015, 328, 12-20. [CrossRef] [PubMed]

35. Oliveira, P.F.; Tomas, G.D.; Dias, T.R.; Martins, A.D.; Rato, L.; Alves, M.G.; Silva, B.M. White tea consumption restores sperm quality in prediabetic rats preventing testicular oxidative damage. Reprod. Biomed. Online 2015, 31, 544-556. [CrossRef] [PubMed]

36. Baker, M.A.; Cerniglia, G.J.; Zaman, A. Microtiter plate assay for the measurement of glutathione and glutathione disulfide in large numbers of biological samples. Anal. Biochem. 1990, 190, 360-365. [CrossRef]

37. Oguntibeju, O.O.; Meyer, S.; Aboua, Y.G.; Goboza, M. Hypoxis hemerocallidea Significantly Reduced Hyperglycaemia and Hyperglycaemic-Induced Oxidative Stress in the Liver and Kidney Tissues of Streptozotocin-Induced Diabetic Male Wistar Rats. Evid. Based Complementary Altern. Med. 2016, 2016, 8934362. [CrossRef] [PubMed]

38. Alves, M.G.; Oliveira, P.J.; Carvalho, R.A. Substrate selection in hearts subjected to ischemia/reperfusion: Role of cardioplegic solutions and gender. NMR Biomed. 2011, 24, 1029-1037. [CrossRef] [PubMed]

39. Wishart, D.S.; Feunang, Y.D.; Marcu, A.; Guo, A.C.; Liang, K.; Vazquez-Fresno, R.; Sajed, T.; Johnson, D.; Li, C.; Karu, N.; et al. HMDB 4.0: The human metabolome database for 2018. Nucleic Acids Res. 2018, 46, D608-D617. [CrossRef] [PubMed]

40. Jarak, I.; Carrola, J.; Barros, A.S.; Gil, A.M.; Pereira, M.L.; Corvo, M.L.; Duarte, I.F. From the Cover: Metabolism Modulation in Different Organs by Silver Nanoparticles: An NMR Metabolomics Study of a Mouse Model. Toxicol. Sci. 2017, 159, 422-435. [CrossRef]

41. Savorani, F.; Tomasi, G.; Engelsen, S.B. icoshift: A versatile tool for the rapid alignment of 1D NMR spectra. J. Magn. Reson. 2010, 202, 190-202. [CrossRef] [PubMed]

42. Dieterle, F.; Ross, A.; Schlotterbeck, G.; Senn, H. Probabilistic quotient normalization as robust method to account for dilution of complex biological mixtures. Application in 1H NMR metabonomics. Anal. Chem. 2006, 78, 4281-4290. [CrossRef] [PubMed]

43. Triba, M.N.; Le Moyec, L.; Amathieu, R.; Goossens, C.; Bouchemal, N.; Nahon, P.; Rutledge, D.N.; Savarin, P. PLS/OPLS models in metabolomics: The impact of permutation of dataset rows on the K-fold cross-validation quality parameters. Mol. Biosyst. 2015, 11, 13-19. [CrossRef] [PubMed]

44. Berben, L.; Sereika, S.M.; Engberg, S. Effect size estimation: Methods and examples. Int. J. Nurs. Stud. 2012, 49, 1039-1047. [CrossRef] [PubMed]

45. van Dijk, S.M.; Hallensleben, N.D.; van Santvoort, H.C.; Fockens, P.; van Goor, H.; Bruno, M.J.; Besselink, M.G. Acute pancreatitis: Recent advances through randomised trials. Gut 2017, 66, 2024-2032. [CrossRef] [PubMed]

46. Silva-Vaz, P.; Abrantes, A.M.; Castelo-Branco, M.; Gouveia, A.; Botelho, M.F.; Tralhao, J.G. Multifactorial Scores and Biomarkers of Prognosis of Acute Pancreatitis: Applications to Research and Practice. Int. J. Mol. Sci. 2020, 21, 338. [CrossRef] [PubMed]

47. Cartwright, S.L.; Knudson, M.P. Evaluation of acute abdominal pain in adults. Am. Fam. Physician 2008, 77, 971-978. [PubMed]

48. Li, J.; Zhu, S.F.; Zhao, X.L.; Liu, Y.X.; Wan, M.H.; Guo, H.; Liu, Y.L.; Gong, H.L.; Chen, G.Y.; Tang, W.F. Metabolomic profiles illuminate the efficacy of Chinese herbal Da-Cheng-Qi decoction on acute pancreatitis in rats. Pancreatology 2015, 15, 337-343. [CrossRef] [PubMed]

49. Zhao, X.; Chen, D.Z.; Lang, R.; Jin, Z.K.; Fan, H.; Wu, T.M.; Li, X.L.; He, Q. Enhanced recovery in the management of mild gallstone pancreatitis: A prospective cohort study. Surg. Today 2013, 43, 643-647. [CrossRef] [PubMed]

50. Khanna, A.K.; Meher, S.; Prakash, S.; Tiwary, S.K.; Singh, U.; Srivastava, A.; Dixit, V. Comparison of Ranson, Glasgow, MOSS, SIRS, BISAP, APACHE-II, CTSI Scores, IL-6, CRP, and procalcitonin in predicting severity, organ failure, pancreatic necrosis, and mortality in acute pancreatitis. HPB Surg. 2013, 2013, 367581. [CrossRef] [PubMed]

51. Al-Nawas, B.; Krammer, I.; Shah, P.M. Procalcitonin in diagnosis of severe infections. Eur. J. Med. Res. 1996, 1, 331-333. [PubMed]

52. Gu, L.; Ma, X.; Wang, L.; Li, H.; Chen, L.; Li, X.; Zhang, Y.; Xie, Y.; Zhang, X. Prognostic value of a systemic inflammatory response index in metastatic renal cell carcinoma and construction of a predictive model. Oncotarget 2017, 8, 52094-52103. [CrossRef] [PubMed] 
53. Chen, L.; Kong, X.; Wang, Z.; Wang, X.; Fang, Y.; Wang, J. Pretreatment Systemic Inflammation Response Index in Patients with Breast Cancer Treated with Neoadjuvant Chemotherapy as a Useful Prognostic Indicator. Cancer Manag. Res. 2020, 12, $1543-1567$. [CrossRef] [PubMed]

54. Cardoso, F.S.; Ricardo, L.B.; Oliveira, A.M.; Horta, D.V.; Papoila, A.L.; Deus, J.R.; Canena, J. C-Reactive Protein at 24 Hours after Hospital Admission may have Relevant Prognostic Accuracy in Acute Pancreatitis: A Retrospective Cohort Study. GE Port. J. Gastroenterol. 2015, 22, 198-203. [CrossRef] [PubMed]

55. Kulaksiz, H.; Fein, E.; Redecker, P.; Stremmel, W.; Adler, G.; Cetin, Y. Pancreatic b-cells express hepcidin, an iron-uptake regulatory peptide. J. Endocrinol. 2008, 197, 241-250. [CrossRef] [PubMed]

56. Babitt, J.L.; Huang, F.W.; Wrighting, D.M.; Xia, Y.; Sidis, Y.; Samad, T.A.; Campagna, J.A.; Chung, R.T.; Schneyer, A.L.; Woolf, C.J. Bone morphogenetic protein signaling by hemojuvelin regulates hepcidin expression. Nat. Genet. 2006, 38, 531. [CrossRef] [PubMed]

57. Perez, S.; Pereda, J.; Sabater, L.; Sastre, J. Redox signaling in acute pancreatitis. Redox Biol. 2015, 5, 1-14. [CrossRef] [PubMed]

58. Song, J.Y.; Lim, J.W.; Kim, H.; Morio, T.; Kim, K.H. Oxidative stress induces nuclear loss of DNA repair proteins Ku70 and Ku80 and apoptosis in pancreatic acinar AR42J cells. J. Biol. Chem. 2003, 278, 36676-36687. [CrossRef] [PubMed]

59. Abu-Hilal, M.; McPhail, M.J.; Marchand, L.; Johnson, C.D. Malondialdehyde and superoxide dismutase as potential markers of severity in acute pancreatitis. JOP J. Pancreas 2006, 7, 185-192.

60. Marek, G.; Ściskalska, M.; Grzebieniak, Z.; Milnerowicz, H. Decreases in Paraoxonase-1 Activities Promote a Pro-inflammatory Effect of Lipids Peroxidation Products in Non-smoking and Smoking Patients with Acute Pancreatitis. Int. J. Med. Sci. 2018, 15, 1619-1630. [CrossRef] [PubMed]

61. Sajewicz, W.; Milnerowicz, S.; Nabzdyk, S. Blood plasma antioxidant defense in patients with pancreatitis. Pancreas 2006, 32, 139-144. [CrossRef] [PubMed]

62. Abreu, F.F.; Souza, A.C.A.; Teixeira, S.A.; Soares, A.G.; Teixeira, D.F.; Soares, R.C.; Santana, M.T.; Lauton Santos, S.; Costa, S.K.P.; Muscará, M.N.; et al. Elucidating the role of oxidative stress in the therapeutic effect of rutin on experimental acute pancreatitis. Free Radic. Res. 2016, 50, 1350-1360. [CrossRef] [PubMed]

63. Bopanna, S.; Nayak, B.; Prakash, S.; Shalimar; Mahapatra, S.J.; Garg, P.K. Increased oxidative stress and deficient antioxidant levels may be involved in the pathogenesis of idiopathic recurrent acute pancreatitis. Pancreatology 2017, 17, 529-533. [CrossRef] [PubMed]

64. Jarak, I.; Almeida, S.; Carvalho, R.A.; Sousa, M.; Barros, A.; Alves, M.G.; Oliveira, P.F. Senescence and declining reproductive potential: Insight into molecular mechanisms through testicular metabolomics. Biochim. Biophys. Acta Mol. Basis Dis. 2018, 1864, 3388-3396. [CrossRef] [PubMed]

65. Wang, J.; Ma, C.; Liao, Z.; Tian, B.; Lu, J.P. Study on chronic pancreatitis and pancreatic cancer using MRS and pancreatic juice samples. World J. Gastroenterol. 2011, 17, 2126-2130. [CrossRef] [PubMed]

66. Jeurnink, S.M.; Nijs, M.M.; Prins, H.A.; Greving, J.P.; Siersema, P.D. Antioxidants as a treatment for acute pancreatitis: A meta-analysis. Pancreatology 2015, 15, 203-208. [CrossRef] [PubMed]

67. Kim, H. Glutamine as an immunonutrient. Yonsei Med. J. 2011, 52, 892-897. [CrossRef] [PubMed]

68. Grimble, R.F. The Interaction Between Nutrition and Inflammatory Stress Throughout the Life Cycle. In Nutrients, Stress and Medical Disorders; Yehuda, S., Mostofsky, D.I., Eds.; Humana Press: Totowa, NJ, USA, 2005; pp. 387-424.

69. Tang, M.; Hu, G.; Zhao, Y.; Su, M.; Wang, Y.; Jia, W.; Qiu, Y.; Liu, G.; Wang, X. A serum metabolomic investigation on lipoprotein lipase-deficient mice with hyperlipidemic pancreatitis using gas chromatography/mass spectrometry. Biomed. Rep. 2013, 1, 469-473. [CrossRef] [PubMed]

70. Dong, Y.W.; Jiang, W.D.; Liu, Y.; Wu, P.; Jiang, J.; Kuang, S.Y.; Tang, L.; Tang, W.N.; Zhang, Y.A.; Zhou, X.Q.; et al. Threonine deficiency decreased intestinal immunity and aggravated inflammation associated with NF-kappaB and target of rapamycin signalling pathways in juvenile grass carp (Ctenopharyngodon idella) after infection with Aeromonas hydrophila. Br. J. Nutr. 2017, 118, 92-108. [CrossRef] [PubMed]

71. Huang, S.S.; Lin, J.Y.; Chen, W.S.; Liu, M.H.; Cheng, C.W.; Cheng, M.L.; Wang, C.H. Phenylalanine- and leucine-defined metabolic types identify high mortality risk in patients with severe infection. Int. J. Infect. Dis. 2019, 85, 143-149. [CrossRef]

72. Biczo, G.; Vegh, E.T.; Shalbueva, N.; Mareninova, O.A.; Elperin, J.; Lotshaw, E.; Gretler, S.; Lugea, A.; Malla, S.R.; Dawson, D.; et al. Mitochondrial Dysfunction, Through Impaired Autophagy, Leads to Endoplasmic Reticulum Stress, Deregulated Lipid Metabolism, and Pancreatitis in Animal Models. Gastroenterology 2018, 154, 689-703. [CrossRef] [PubMed]

73. Szymanska, E.; Frydenvang, K.; Pickering, D.S.; Krintel, C.; Nielsen, B.; Kooshki, A.; Zachariassen, L.G.; Olsen, L.; Kastrup, J.S.; Johansen, T.N. Studies on Aryl-Substituted Phenylalanines: Synthesis, Activity, and Different Binding Modes at AMPA Receptors. J. Med. Chem. 2016, 59, 448-461. [CrossRef] [PubMed] 